\title{
The perception of medical residents and faculty members on resident duty hour regulation
}

\author{
Eui-Ryoung Han and Eun-Kyung Chung
}

Department of Medical Education, Chonnam National University Medical School, Hwasun, Korea

Purpose: This study investigated the perceptions of medical residents and faculty members before the implementation of the duty hour regulation in December 2017.

Methods: A survey was administered to 263 residents and 358 faculty members in the Chonnam National University Hospital. The subjects were given a self-administered structured questionnaire designed to measure their perspectives on duty hour regulation. They were also asked to answer an open-ended question regarding their expectations or concerns regarding duty hour regulation. The response rates were $50.2 \%$ for residents and $24.0 \%$ for faculty members.

Results: Residents and faculty members regarded the improvement of junior residents' well-being favorably, but had conflicting views regarding senior residents. Residents expressed difficulty in completing unchanged workloads within the limited time, while faculty members were more concerned about worsening patient safety due to the discontinuity of care and insufficient resident education.

Conclusion: Medical residents and faculty members had differing concerns regarding duty hour regulation. Further studies and the development of future policies should be considered to improve resident education and patient safety within the limited duty hour regulation.

Key Words: Internship and residency, Quality of life, Graduate medical education, Patient safety

\section{Introduction}

In December 2017, the resident duty hour regulation was first implemented in Korea; it was designed to protect the rights of residents, contribute to high-quality resident education, and improve patient safety. However, its effects on patient safety and resident education remain controversial. Residents and residency program directors, who already have work-hour restrictions, believed that quality of patient care and resident edu- cation would be negatively affected by the regulation $[1,2]$.

In Korea, several reports have warned of the existence of substandard working environments, including excessive workloads, sleep deprivation, and emotional exhaustion $[3,4]$. Therefore, the regulation was implemented and teaching hospitals in Korea were given a 1 -year grace period to prepare for the new training environment. Duty hour regulation limits work hours as follows: maximum hours of work are limited to 80 hours per week, averaged over 4 weeks, including nightshifts;
Received: February 6, 2020 • Revised: February 17, 2020 • Accepted: February 20, 2020 Corresponding Author: Eun-Kyung Chung (https://orcid.org/0000-0002-3595-0220)

Department of Medical Education, Chonnam National University Medical School, 264 Seoyang-ro, Hwasun-eup, Hwasun 58128, Korea

Tel: +82.61.379.2602 Fax: +82.62.232.9708 email: ekcmedu@chonnam.ac.kr
Korean J Med Educ 2020 Mar; 32(1): 67-72.

https://doi.org/10.3946/kjme.2020.154

eISSN: 2005-7288

(C) The Korean Society of Medical Education. All rights reserved. This is an open-access article distributed under the terms of the Creative Commons Attribution Non-Commercial License (http:// creativecommons.org/licenses/by-nc/3.0/), which permits unrestricted non-commercial use, distribution, and reproduction in any medium, provided the original work is properly cited. 
maximum hours of consecutive duty do not exceed 36 hours; and minimum off-duty time between duty shifts should be guaranteed 10 hours. Despite the implementation of this regulation, there has been a report evaluating the superiority of a night float system with regard to duty hours [5].

In order to ensure that these new changes in graduate medical education develop into a successful system, we should listen to residents and faculty members who have first-hand experience of the duty hour regulation. Teaching hospitals comprise loosely coupled organizations whose members, including residents and faculty members, have strong autonomy to set their own priorities and resist control by authorities [6]. To improve the training environment, we investigated their perception of duty hour regulation, how they have accepted it, and what they want out of it. The specific research questions were as follows: (1) How did the residents and faculty members perceive the new duty hour regulation before the law was enforced? (2) What did they expect or what were their concerns, regarding this regulation, in preparation for the new training environment?

\section{Methods}

A total of 263 residents and 358 faculty members were recruited from the main and Hwasun regional branches of the Chonnam National University Hospital. The study was approved by review by the Chonnam National University Hospital Institutional Review Board (IRB approval no., CNUH-2017-003).

\section{Data collection}

We developed a self-administered structured questionnaire in light of the results of former research [1,2].
The questionnaire was sent by post to each department of the hospitals prior to the implementation. The questionnaire consisted of three sections. The first section asked for demographic information. The second section asked about the respondents' levels of agreement on each item of resident duty hour regulation, on a 5-point Likert scale, and asked for their perceived effects of duty hour regulation on quality of life, resident education, and patient care. These questions required either a positive, neutral, or negative response. The third section asked about the respondents' expectations or concerns regarding the new regulation; this was an optional and free-text response question.

Data were collected between November and December 2017 which was the last month of the 1-year grace period. All data were provided anonymously.

\section{Data analysis}

We performed a chi-square test and Student $\mathrm{t}$-test to compare the general characteristics of the participants and their perceptions about the resident duty hour regulation between residents and faculty members. All analyses were performed using IBM SPSS Statistics ver. 25.0 (IBM Corp., Armonk, USA).

\section{Results}

We received 132 responses (50.2\%) from residents and 86 responses (24.0\%) from faculty members. The demographic information of the respondents is summarized in Table 1.

\section{Level of agreement and perceived effect of duty hour regulation}

The residents and faculty members positively answered in agreement on each item of resident duty hour 


\begin{tabular}{|c|c|c|c|}
\hline Characteristic & Medical residents $(n=132)$ & Faculty members $(n=86)$ & $\mathrm{p}$-value \\
\hline Gender & & & 0.167 \\
\hline Male & 95 (72.0) & $69(80.2)$ & \\
\hline Female & $37(28.0)$ & $17(19.8)$ & \\
\hline Age (yr) & $29.4 \pm 2.9$ & $42.1 \pm 7.9$ & $<0.001$ \\
\hline Specialty ${ }^{\text {al }}$ & & & 0.117 \\
\hline Medical & $69(52.3)$ & $36(41.9)$ & \\
\hline Surgical & $36(27.3)$ & $35(40.7)$ & \\
\hline Diagnostic & $27(20.5)$ & $15(17.4)$ & \\
\hline \multicolumn{4}{|l|}{ Year of training } \\
\hline $1 \mathrm{st}$ & 43 (32.8) & & \\
\hline 2nd & $36(27.5)$ & & \\
\hline $3 r d$ & $38(29.0)$ & & \\
\hline 4th & $14(10.7)$ & & \\
\hline \multicolumn{4}{|l|}{ Academic position } \\
\hline Tenure-track professor & & $40(46.5)$ & \\
\hline Non-tenure-track professor & & $11(12.8)$ & \\
\hline Clinical instructor & & $35(40.7)$ & \\
\hline
\end{tabular}

Data are presented as number $(\%)$ or mean \pm standard deviation.

${ }^{\text {al } M e d i c a l}$ specialty includes internal medicine, pediatrics, psychiatry, neurology, dermatology, emergency medicine, family medicine, rehabilitation medicine, radiation oncology, and anesthesiology. Surgical specialty includes general surgery, obstetrics and gynecology, orthopedic surgery, neurosurgery, thoracic surgery, plastic surgery, ophthalmology, otorhinolaryngology, and urology. Diagnostic specialty refers to laboratory medicine, radiology, nuclear medicine, and pathology.

Table 2. Agreement on Resident Duty Hour Regulation

\begin{tabular}{lccc}
\hline \multicolumn{1}{c}{ Variable } & Medical residents $(\mathrm{n}=132)$ & Faculty members $(\mathrm{n}=86)$ & $\mathrm{p}$-value \\
\hline Maximum duty of $80 \mathrm{hr} /$ wk laveraged over 4 wk) & $3.83 \pm 0.93$ & $3.84 \pm 1.06$ & 0.944 \\
Maximum consecutive duty hours <36 hr & $4.06 \pm 0.85$ & $4.02 \pm 0.93$ & 0.761 \\
Mandatory 10 hr off between shifts & $3.98 \pm 0.85$ & $3.69 \pm 1.13$ & 0.044 \\
\hline
\end{tabular}

Data are presented as mean \pm standard deviation. The level of agreement on resident duty hour regulation was described using a 5-point Likert scale.

regulation (Table 2). The perceived effects of duty hour regulation on quality of life for junior residents were favored by both residents and faculty members. However, those for senior residents were contrary to each other $(\mathrm{p}<0.001)$ (Table 3). Residents and faculty members had diverse opinions about the effects on patient care and resident education. Faculty members were more worried about the negative effect on continuity of patient care than medical residents $(\mathrm{p}=0.007)$. The majority of the residents believed that the quality of resident education and the preparation for a more senior resident role would remain unchanged. Conversely, faculty members had more negative responses, expressing that these factors would be made worse by the new regulation.

\section{Expectations or concerns regarding duty hour regulation}

The most popular opinion of residents and faculty members alike was to reduce the workloads of residents, instead of merely restricting their duty hours. Residents argued that it was more difficult to complete unchanged workloads within the limited duty hour. It was harder to assign unchanged workloads to residents if their specialty was unpopular. Both groups suggested that a professional workforce, including hospitalists or phy- 
Table 3. Perceived Effects of Duty Hour Regulation between Residents and Faculty members

\begin{tabular}{|c|c|c|c|c|c|}
\hline Variabgle & Category & Worse or decreased & Unchanged & Better or increased & $\mathrm{p}$-value \\
\hline \multirow{2}{*}{ Quality of life for junior residents } & Medical residents & $2(1.6)$ & $46(35.7)$ & $81(62.8)$ & 0.010 \\
\hline & Faculty members & $1(1.2)$ & $14(16.7)$ & $69(82.1)$ & \\
\hline \multirow[t]{2}{*}{ Quality of life for senior residents } & Medical residents & $65(50.0)$ & $31(23.8)$ & $34(26.2)$ & $<0.001$ \\
\hline & Faculty members & $17(20.2)$ & $11(13.1)$ & $56(66.7)$ & \\
\hline \multirow[t]{2}{*}{ Work schedules } & Medical residents & $16(12.3)$ & $47(36.2)$ & $67(51.5)$ & $<0.001$ \\
\hline & Faculty members & $5(6.0)$ & $13(15.5)$ & $66(78.6)$ & \\
\hline \multirow[t]{2}{*}{ Amount of rest } & Medical residents & $6(4.6)$ & $46(35.4)$ & $78(60.0)$ & $<0.001$ \\
\hline & Faculty members & 0 & $9(10.7)$ & 75 (89.3) & \\
\hline \multirow[t]{2}{*}{ Patient safety } & Medical residents & $19(14.6)$ & $55(42.3)$ & $56(43.1)$ & 0.040 \\
\hline & Faculty members & $23(27.7)$ & $25(30.1)$ & $35(42.2)$ & \\
\hline \multirow[t]{2}{*}{ Quality of patient care } & Medical residents & $14(10.8)$ & $61(46.9)$ & $55(42.3)$ & 0.006 \\
\hline & Faculty members & $23(27.4)$ & $29(34.5)$ & $32(38.1)$ & \\
\hline \multirow[t]{2}{*}{ Continuity of patient care } & Medical residents & $32(24.6)$ & $50(38.5)$ & 48 (36.9) & 0.007 \\
\hline & Faculty members & $38(45.2)$ & $24(28.6)$ & $22(26.2)$ & \\
\hline \multirow[t]{2}{*}{ Quality of resident education } & Medical residents & $19(14.6)$ & $65(50.0)$ & $46(35.4)$ & $<0.001$ \\
\hline & Faculty members & $32(38.1)$ & $22(26.2)$ & 30 (35.7) & \\
\hline \multirow[t]{2}{*}{ Preparation for more senior resident role } & Medical residents & $26(20.0)$ & $56(43.1)$ & 48 (36.9) & 0.033 \\
\hline & Faculty members & $30(36.1)$ & 28 (33.7) & $25(30.1)$ & \\
\hline \multirow[t]{2}{*}{ Availability of supervision } & Medical residents & $10(7.8)$ & 72 (55.8) & $47(36.4)$ & $<0.001$ \\
\hline & Faculty members & 24 (28.9) & 37 (44.6) & $22(26.5)$ & \\
\hline
\end{tabular}

Data are presented as number $(\%)$.

sician assistants, should be recruited to share the work burden.

Residents anticipated that duty hour regulation would help them to more easily secure off-duty time and time for studies. However, faculty members were more concerned that the discontinuity of patient care would hamper professional development, including the responsibility of patients, and eventually cause the deterioration of patient safety. Duty hour regulation could impede resident education because of fewer clinical experiences as a result of their shortened time and the segmented process of patient care, especially when attending operations that take a long time. Faculty members recommended that there should be education programs or research activities outside of the hospital for residents, to compensate resident education and ultimately, improve patient safety.

\section{Discussion}

Our study showed that residents and faculty members agreed on the positive effect on junior residents' well-being. However, they had differing viewpoints about the effects of the regulation. Residents expressed the difficulty of completing unchanged workloads within the limited hours, while faculty members were more concerned about worsening patient safety due to the discontinuity of care and insufficient resident education.

Residents complained of the difficulty in making a schedule without exceeding someone's working hours, given a fixed number of residents. Residents expected that senior residents' quality of life would be worse since senior residents could assume part of the work from junior residents, as compared with the practices of previous training years. To ameliorate their intense and concentrated workloads, they suggested that existing 
members should be redistributed, and that a professional workforce should be recruited. The recruitment of new members of the workforce would be essential to sustain a successful change of graduate medical education if labor costs may be offset by the reduction in costs related to preventable adverse events [7].

Faculty members expressed concerns that resident education would be negatively affected by decreased opportunities for clinical exposure. Consequently, duty hour regulation would result in delayed preparation for more senior resident roles and increased duration of training [1]. However, duty hour regulation was not associated with differences in resident examination performance [8]. Residents, in our study, were rather delighted to secure off-duty time and time for studies. Indeed, the residents perceived that their opportunities for learning were influenced by the content and organization of duty hours, rather than the volume of duty hours [9]. A safe and humanistic education environment would be the most important factor for residents' learning, given a high level of well-being and sufficient high-quality supervision [9].

In our study, residents and faculty members had mixed opinions regarding the effects of the regulation on patient care. Despite concerns about increased handoffs, discontinuity of care, and decreased ownership of patients, there have been no objective values of worsened patient outcomes, in accordance with previous research $[8,10]$. High levels of emotional burnout and depression have been connected with more medical errors and poorer clinical performance [1,8].

This study has several limitations. First, this research was an observational study to survey participants' perceptions of duty hour regulation. Thus, there was potential for interpretation and recall bias. The study may have been affected by selection bias because it was both anonymous and voluntary. Second, it was restricted to the main and regional branches of a teaching hospital in one province, and therefore should not be generalized. However, it represents a very meaningful first step towards investigating the perceptions of residents and faculty members on the duty hour regulation. These results would be useful to identify and consider their desires regarding the management of the residency training program considering our medical environments, although the numerous reports of other countries might be a good guide to indicate the long-term consequences of duty hour restrictions [1,2,8-10].

Further research should be conducted to examine changes in perceptions after the implementation of the regulation. A qualitative study could also be undertaken to gain a broader understanding of perceptions of the duty hour regulation. A nationwide survey will be required to determine the effects of the duty hour regulation on resident well-being, patient outcomes, and resident performance, all of which are relevant to our training environment.

In conclusion, residents and faculty members had differing concerns regarding duty hour regulation. Further studies and the development of future policies should be considered to improve resident education and patient safety within the limited duty hour regulation.

\section{ORCID:}

Eui-Ryoung Han: https://orcid.org/0000-0002-6781-432X; Eun-Kyung Chung: https://orcid.org/0000-0002-3595-0220 Acknowledgements: None.

Funding: This study was supported by a grant (CRI 16 032-1) Chonnam National University Hospital Biomedical Research Institute.

Conflicts of interest: No potential conflict of interest relevant to this article was reported.

Author contributions: $\mathrm{ERH}$ and EKC contributed to 
setting the concept, designing the research, and to the acquisition and analysis of data. ERH contributed to drafting the manuscript, and EKC critically revised the manuscript. All authors approved the final manuscript for publication, and have agreed to be accountable for all aspects of the work.

\section{References}

1. Drolet BC, Christopher DA, Fischer SA. Residents' response to duty-hour regulations: a follow-up national survey. N Engl J Med. 2012;366(24):e35.

2. Drolet BC, Khokhar MT, Fischer SA. The 2011 dutyhour requirements: a survey of residency program directors. N Engl J Med. 2013;368(8):694-697.

3. Kim SR, Kim SS, Kim JY. Working condition, health and perceived patient safety among doctors in training: 2014 Korean interns \& residents survey. Health Soc Welf Rev. 2015;35(2):584-607.

4. Oh SH, Kim JS, Lee PS. A survey on training and working conditions of residents in 2015. J Korean Med Assoc. 2015;58(12):1179-1189.
5. Yu HW, Choi JY, Park YS, et al. Implementation of a resident night float system in a surgery department in Korea for 6 months: electronic medical record-based big data analysis and medical staff survey. Ann Surg Treat Res. 2019;96(5):209-215.

6. Shin JS. Leadership challenges in the advancement of medical education. Hanyang Med Rev. 2012;32(1):1-7.

7. Nuckols TK, Bhattacharya J, Wolman DM, Ulmer C, Escarce JJ. Cost implications of reduced work hours and workloads for resident physicians. $\mathrm{N}$ Engl J Med. 2009;360(21):2202-2215.

8. Rajaram R, Chung JW, Jones AT, et al. Association of the 2011 ACGME resident duty hour reform with general surgery patient outcomes and with resident examination performance. JAMA. 2014;312(22):2374-2384.

9. Sundberg K, Frydén H, Kihlström L, Nordquist J. The Swedish duty hour enigma. BMC Med Educ. 2014;14 Suppl 1(Suppl 1):S6.

10. Patel MS, Volpp KG, Small DS, et al. Association of the 2011 ACGME resident duty hour reforms with mortality and readmissions among hospitalized Medicare patients. JAMA. 2014;312(22):2364-2373. 